\title{
Critical Imaginaries and Reflections on Artificial Intelligence and Robots in Postdigital K-12 Education
}

\author{
Stefan Hrastinski ${ }^{1}$ (D) Anders D. Olofsson ${ }^{2} \cdot$ Charlotte Arkenback $^{3}$. \\ Sara Ekström ${ }^{4}$. Elin Ericsson ${ }^{3}$. Göran Fransson ${ }^{5}$. Jimmy Jaldemark ${ }^{6}$. \\ Thomas Ryberg ${ }^{7}$. Lena-Maria Öberg ${ }^{8}$. Ana Fuentes ${ }^{4}$. Ulrika Gustafsson ${ }^{2}$. \\ Niklas Humble $^{8} \cdot$ Peter Mozelius $^{8} \cdot$ Marcus Sundgren $^{6} \cdot$ Marie Utterberg $^{3}$
}

\begin{abstract}
It is commonly suggested that emerging technologies will revolutionize education. In this paper, two such emerging technologies, artificial intelligence (AI) and educational robots (ER), are in focus. The aim of the paper is to explore how teachers, researchers and pedagogical developers critically imagine and reflect upon how AI and robots could be used in education. The empirical data were collected from discussion groups that were part of a symposium. For both AI and ERs, the need for more knowledge about these technologies, how they could preferably be used, and how the emergence of these technologies might affect the role of the teacher and the relationship between teachers and students, were outlined. Many participants saw more potential to use AI for individualization as compared with ERs. However, there were also more concerns, such as ethical issues and economic interests, when discussing AI. While the researchers/developers to a greater extent imagined ideal future technology-rich educational practices, the practitioners were more focused on imaginaries grounded in current practice.
\end{abstract}

Keywords Artificial intelligence $\cdot$ Educational robots $\cdot$ Postdigital education $\cdot$ K-12 education $\cdot$ Automation $\cdot$ Symposium

\section{Introduction}

Education is becoming increasingly digital. Today, digital technologies, such as computers, tablets and interactive whiteboards are common in K-12 classroom. Arguments that emerging technologies have the potential to revolutionize education are common. In this paper, two such emerging technologies, artificial intelligence in education

Stefan Hrastinski

stefanhr@kth.se

Extended author information available on the last page of the article 
(AIED) and educational robots (ER), are in focus. In the literature, AIED and ERs show some promise in educational activities such as driving educational development (Alberola et al. 2016; Park and Han 2016), providing support to teachers and the teaching practice (Edwards and Cheok 2018; Yun et al. 2013) and in scaffolding students' learning processes (Samani et al. 2017; Serholt 2017). Acknowledging the potentials of using AIED and robots in education, there are at the same time many educational, policy and ethical questions in need of further critical reflection. One such question is the role of the teacher in postdigital educational practices. We use the term postdigital education because we prefer not to distinguish between digital and nondigital education. Fawns (2018: 132) critically discusses this dichotomy and argues that the terms 'become problematic when used to close down ideas or attribute essential properties to technology'. The postdigital perspective contends that all education, even education that is not considered to be digital, takes account of the digital and the nondigital in the design and practice of educational activities. AIED and ERs are being used alongside both digital and non-digital practices in postdigital K-12 education.

Research on the role of the teacher in the digitalized K-12 classroom includes several focus. For example, teachers' beliefs in teaching with technology (Prestridge 2012), teachers' professional development in the use of digital technology (Lantz-Andersson et al. 2017), teachers' agency in the digitalized classroom (Albion and Tondeur 2018), teachers' design of digitalized teaching and learning activities (Jahnke et al. 2017) and teachers' digital competence (Krumsvik 2008; Krumsvik et al. 2016; Fransson et al. 2018; Lindberg and Olofsson 2018). The last strand of research, teachers' digital competence, appears to be of special interest in relation to what an increased presence of AIED and ERs in the K-12 classroom could mean for the role of the teacher. For example, it might mean that teachers need to be digitally competent (a) in using such digital technologies in a way where technology, pedagogy and content intertwine, (b) in relation to ethical issues, or put differently, teachers needs to grapple the fact that both AIED and ERs can collect, store and analyse information about the users (e.g. the teacher and the student), and (c) in identifying and participating in professional development activities providing opportunities to experiment with, and learn more about, emergent digital technologies.

Another way to think about the role of the teacher and emerging technologies such as AIED and ERs in K-12 schools could be by asking: who is driving this development? Is it the teachers, the students, the school leaders, the parents or commercial interests? Business interests might set the agenda for how teachers' role and agency are shaped or even worse substantially diminished (Player-Koro et al. 2018; Williamson 2016). To us, such a development also raises the question of the future role of the teacher in terms of democracy and equality in a postdigital education era, where AIED and ERs might (or might not) be commonly used. Thus, it becomes critical that practitioners, such as teachers, school leaders and policy makers, and researchers, from various disciplines, critically discuss the role of AIED and ER in postdigital education.

It is of specific interest in this paper to put the concept of sociotechnical imaginaries in relation to the role of the teacher in postdigital K-12 education. Sociotechnical imaginaries are useful in this context, since we are exploring the imagined impact of AIED and ERs - an impact not yet being stabilized in K-12 education. The use of the 
theoretical concept of sociotechnical imaginaries in this paper is inspired by the work of Williamson (2016: 42), and his idea about a desirable future that can be produced by social groups, located in certain settings with certain areas of interest, and '[...] projected through the design of particular kinds of technologies to express a view of particular futures in which those kinds of technologies are imagined to be integral, embedded parts'. The reason behind using sociotechnical imaginaries in this paper, rather than speaking of 'the future' of postdigital K-12 education is to highlight that the future is (obviously) not set in stone. Put differently, acknowledging that, when speaking of the future of education, we as researchers and teachers are, in fact, always part of producing and promoting particular sociotechnical imaginaries, including their potential meaning, affordances and constraints in various educational settings. Moreover, in discussing sociotechnical imaginaries and the role of the teacher, it seems useful also to bring in the distinction between state-of-the-art and state-of-the-actual as proposed by Henderson et al. (2015). This refers to what might ideally be achieved by using emerging digital technology in contemporary K-12 education, and the realities of actual and everyday use of such technology in the classroom. We believe a similar distinction can also be used when discussing sociotechnical imaginaries. Do our imaginaries stem from researchers who are imagining ideal future technology-rich educational practices or from the perspective of practitioners grounded in current practice? In this paper, we combine and contrast both perspectives.

This paper explores how teachers, researchers, and pedagogical developers critically imagine and reflect upon how artificial intelligence (AI) and robots could be used in education. AIED and ERs are useful examples, because they are commonly used when imaging 'futures' of education. Such technologies are often present at trade shows and other educational events, but not yet commonly used in K-12 classrooms. The paper is guided by the following research questions:

RQ1: Which imaginaries and reflections emerged when teachers and researchers/ developers discussed the use of AI in postdigital K-12 education?

RQ2: Which imaginaries and reflections emerged when teachers and researchers/ developers discussed the use of robots in postdigital K-12 education?

\section{Literature Review}

\section{Artificial Intelligence in Education}

The idea of creating intelligent machines and AI can be traced back at least to the fourteenth century. In Ars Magna published in 1315, Llull outlined the idea that reasoning and thought processes might be artificially implemented in an intelligent machine (Jensen 2017). Turing (1937) presented a more modern vision of how intelligent reasoning and calculations could be formalized in intelligent computing machines. Later, Turing (1950) elaborated on his ideas in the article 'Computing Machinery and Intelligence'. This article has become the foundation for modern AI (Castelfranchi 2013), even if the term AI was not coined until 1956, 2 years after Turing's death, by John McCarthy for the Dartmouth Summer Research Project on Artificial Intelligence (McCarthy et al. 2006). 
Attempts to build intelligent thinking machines and formalize intelligent reasoning have formed an ongoing process since Turing built the first chess programme in the 1950s. In a mix of successes and failures, computer programs have beaten grandmasters in chess, but without reaching a lobster's level of social skills and handling real world problems. This conclusion was drawn by Searle (1990), who also has created the division between strong AI and weak AI. Strong AI could be exemplified with the Turing test, where true AI is accomplished when it is no longer possible to tell the difference between a natural language conversation between a human and an AI system, and a conversation between two humans (compare Turing 1950). Weak AI denotes less complex practical applications of AI such as two digital devices communicating by Bluetooth, or when the Stockfish chess engine plays against a human chess player. According to Lee and Shin (2017), the vast majority of developed AI systems so far can be categorized as a weak AI while strong AI solutions still lay in the future.

There are many ways of criticizing the development of AI which could be taken into account in the context of postdigital K-12 education and the role of the teacher. These critiques can be classified in two main categories: (1) the technical problem and (2) the social and ethical implications. The first kind of criticism has, for example, been discussed by Dreyfus and Dreyfus (1988) who raise questions and concerns surrounding the technical issues in developing intelligent traits in AI (such as common-sense, natural language and self-awareness) and claim that the complexity of these problems risks being overly simplified by AI optimism derived from economic interests in making AI a reality, not least in postdigital K-12 settings (compare Williamson 2016).

The second kind of criticism has, amongst others, been raised by Tegmark (2017), who discusses the potential role of humans in a future with AI and what our own intelligence limitations are in making informed conclusions on whether it is in our own interest to pursue development of AI. According to Tegmark (2017), questions that might turn into reality in the future, and therefore need to be discussed already today, include: If AI surpasses human intelligence, what use will it have for humans? If we try to contain and control AI that surpasses human intelligence, how sure can we be that it will not break free or trick us into letting it free?

According to Roll and Wylie (2016), AI has achieved success in several fields, such as technical development (VanLehn 2011) over the past 25 years and has made an impact on education (Koedinger and Corbett 2006; Heffernan and Heffernan 2014). Furthermore, Luckin et al. (2016) provide two examples of the practical use of artificial intelligence in education (AIED) - (1) to support student collaboration and (2) to implement mass individualisation in teaching and learning. During the last 25 years, the AIED community has had a focus on creating interactive learning environments that are as effective as human one-on-one tutoring (VanLehn 2011). From an educational point of view, the most interesting question is not whether AIED will replace the teacher or not, but rather what AIED has a potential to change in relation to the role of the teacher in the postdigital K-12 classroom. One such change has been described by King (1993) in terms of a shift from the 'sage on the stage', to the 'guide on the side'. According to Roll and Wylie (2016), AIED has the potential to free teachers from the burden of possessing all knowledge and information relevant for their students, and teachers instead can support students in seeking, discussing and integrating information in collaborative knowledge-building processes. 


\section{Educational Robots}

The idea of a skilled and intelligent machine has existed in human minds for a very long time. According to Siciliano and Khatib (2018), one of the earliest examples is the legend of the giant Thalos, a bronze slave forged by Hephaestus (3500 BC). Another example of a precursor to thinking machines are the Egyptian oracle statues (2500 BC), having priests hiding inside and simulating machine intelligence. During the eighteenth century, automata (mechanical dolls performing specific tasks) flourished (Siciliano and Khatib 2018). For example, Jacquet-Droz's family of androids played the organ, made drawings, and performed handwriting, producing predetermined pieces of art (Sayous 2009). The word robot was introduced in 1920 by the Czech playwright Karel Čapek, as a derivative of the Czech words robotnik (forced worker), robota (forced labour, drudgery), and robotiti (to work, drudge). The word was picked up and expanded on by science fiction author Isaac Asimov in the 1940s, where he also added an ethical dimension with his 'three laws of robotics' (Asimov 1941; Siciliano and Khatib 2018).

Robots also have a fairly long history in the field of education. One of the most famous examples is Seymour Papert's introduction of the LOGO programming language and the turtle robot (1980), which was later developed to include a physical (non-humanoid) robot that could be controlled. Today, a reasonable level of social interaction between human and machine is technically possible and, according to Serholt (2017), the research interest in this field is growing rapidly. Serholt also claims that the term robot cover different kinds of phenomena ranging from software expert systems to autonomous physical robots. Cheng et al. (2017) and Sharkey (2016) consider that, so far, most research in this field has been directed towards the use of robots in STEM (science, technology, engineering and mathematics) education with the purpose of familiarizing students with programming and mechanics. In this paper, the focus is on ERs with a physical body, social interactive capabilities and some level of AI in accordance with Serholt's (2017) definition. A distinguishing aspect is that ERs can imitate the social role of a teacher, companion or peer (Sharkey 2016).

A recurring argument for the use of ERs is the global shortage of teachers (Edwards and Cheok 2018; Morita et al. 2018). Another argument for the use of ERs is the possibility of individualization and adaptation to different student needs in teaching and learning situations. According to Mubin et al. (2013), the role of ER in the classroom can be described in terms of a peer or tutor in the classroom which in turn has an impact on the role of the teacher placed in the same educational setting. Pandey and Gelin (2017) describe six types of roles for robots in ERs education: (1) teaching assistant, (2) peer and co-learner, (3) companion, (4) entertainer, (5) for telepresence, and (6) as a teaching platform, where the first four have attracted the most research interest. Chevalier et al. (2016) consider that the main motivation for teachers to use an ER in the classroom is that they themselves have an interest in the robot, want to learn something new and to become more efficient professionally. However, both teachers (Serholt 2017) and the general public have worries about the use of ERs in schools (Sharkey 2016). Reporting from a European survey of public attitudes to robots $(N>$ 27,000 ), Sharkey (2016) states that $34 \%$ of the respondents held the opinion that robots should be banned from education and only $3 \%$ of those surveyed thought that robots should be used in education. According to Chevalier et al. (2016), using ERs in real 
school conditions challenges the role of the teacher in relation, for example, to lack of knowledge and policy on how to use ERs in their teaching. Similarly, Alsoliman (2018) felt that teachers lack strategies on how to use ER both in general and specifically in their subjects as well as how to evaluate the suitability of ER in relation to the age of their students. Mubin et al. (2013) suggest that the role of the teacher, the role of the ER and the division of labour have to be clarified before ER can be successfully integrated into classrooms. For example, Serholt et al. (2017) write that ER could be given too much responsibility, which in turn can risk losing important connections between the teacher and ER. Moreover, Serholt and colleagues state that teachers also have concerns about their students regarding data privacy and the negative consequences of students using and interacting with ER. Mubin et al. (2013) describe that ER are mostly used as an add-on activity and in consequence are not yet an integrated part of formal education. Serholt (2017) here point out that a barrier for that to happen may be the lack of support for teachers regarding curricula and teaching materials.

According to a recent meta-review (Belpaeme et al. 2018) ER effect both cognitive and affective outcomes in a similar region to that of human tutors. However, Belpaeme and colleagues also describe that ER are typically deployed in very restricted educational settings with little adaptation to individual learners, so there is nothing suggesting either that ER could replace humans in any general sense or that positive cognitive and positive affective outcomes could be linked together. Edwards et al. (2018) argue that ER's social behaviour may lead to both positive and negative emotions, and as positive outcomes have been found to be associated with feelings of social connectedness, additional studies to better understand how specific behaviours can support connectedness are needed.

\section{Method}

\section{Research Setting}

Data analysed in this paper were collected from an international symposium on the theme 'Digitalisation, education and design: The role of the teacher'. The symposium was hosted by the Mid Sweden University. It included three 30-minute keynotes ${ }^{1}$ followed by group discussions. The first keynote concerned digital competence in education and provided the participants with an overall context for discussing the teacher's role within a common framework. The next two keynotes on AIED and ER focused on concrete aspects of digital applications in education. However, the keynotes differed in character and content. The AIED keynote had a more philosophical approach, whereas the ERs keynote was oriented more practically. This difference between the keynotes might have impacted the subsequent group discussions.

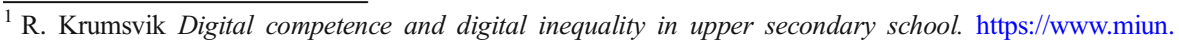
se/en/Research/major-research-initiatives/researchgroups/fodi/ded/abstract-rune-krumsvik/R. Luckin AI in Education: Blending Human Intelligence and Machine Learning https://www.miun.se/en/Research/majorresearch-initiatives/researchgroups/fodi/ded/abstract-rose-luckin/ S. Serholt Social Robots in Education: Moving Beyond the Hype https:/www.miun.se/en/Research/major-research-initiatives/researchgroups/ fodi/ded/sofia-serholt/
} 
The participants in the symposium came mainly from the Nordic countries and included K-12 teachers $(N=25)$ as well as researchers and pedagogical developers $(N=40)$. The participants were divided into nine groups with five to ten participants each under the guidance of a group facilitator. Four of the groups consisted of teachers and five groups included researchers/developers. After each keynote, the groups met in separate rooms for $45 \mathrm{~min}$. In all the groups, the participants were asked to reflect individually and write down their reflections on post-it notes. Thereafter, the post-it notes were first presented to the rest of the group and then discussed and clustered on posters. After the three keynotes and follow-up group discussions, the symposium ended with a closing reflection including short summaries of the discussions in all the nine groups. The group discussions, and more specifically the reflections in the shape of comments on the post-it notes, became the basis for the data analysis. In total, 393 comments appeared on the post-it notes and were included in the analysis.

\section{Data Analysis}

Data from the symposium were elaborated on in a workshop carried out the day after the symposium. In total, the workshop included 15 researchers or $\mathrm{PhD}$ students. After the lead authors of this paper had introduced the idea behind the workshop, including the time frames for the collaborative work on the paper, the colleagues were divided into six subgroups with 2-3 colleagues in each group. Thereafter, each group was appointed responsibility for a different section of the paper. This collaborative approach means that all colleagues had an opportunity to impact the literature review, methodological description, analysis and results, discussion and conclusion. Together, the subgroups worked in an open online document that enabled all authors to continuously reflect upon and comment on the work of the other subgroups. After the end of the workshop, the paper has been finalized by means of an open online document combined with email conversations and Skype meetings. The trustworthiness and credibility of such a collaborative approach to the analysis of data and scientific writing has earlier been applied by some of the participating researchers (Hill et al. 2018; Jandrić 2019; Jandrić et al. 2019).

In the analysis of the data, one of the subgroups worked with the data from the AIED session and another group worked with the data from the ERs session. In this work, two different analyses were applied. First, the data from each session were divided into different themes, which are presented in the 'Results' section. Second, the different themes were quantified using frequency counts based on the number of comments on the post-it notes corresponding to each theme. The analysis was performed with the purpose of finding themes that were emphasized in the two different sessions. Most frequent themes were later delved into deeper in the second round of qualitative analysis. The analysis and results were at a later stage discussed and adjusted in a process which include all authors. Beyond the dimension of content-AIED or ERthe data were also analysed in the dimensions of participants in the symposium. This dimension in the analysis divided the data into two subgroups: data from the four teacher groups, and data from the five researcher/developer groups. This, taken together, allowed the analysis of common concerns as well as alignment gaps and difference 
of opinions between the teachers and the researchers/developers, regarding the applications of AIED and ER.

\section{Results}

In this section, the results of the analysis of the nine group discussions on AIED and ERs during the symposium are presented. First, an overview of the empirical data is provided by means of a presentation of the themes that emerged from the data. This overview should not tempt the reader to draw definite conclusions, but serves merely as an indication of emphasis in the discussions. Second, the most common themes are discussed in more detail.

\section{Comments on Artificial Intelligence in Education}

AIED rendered in total 211 comments (post-its) - 104 comments in 11 themes from the teachers and 107 comments in 10 themes from the researchers/developers (see Table 1). Some of the comments were coded in more than one theme. In comparison, the themes provided an overview of different emphasis in the four groups consisting of teachers and the five groups consisting of researchers/developers. Comparing the themes implies that teachers seemed to be more engaged with issues related to the practice of teaching and learning, or more specifically, the need for professional development in order to take advantage of AIED and how their relationships with students might be affected when using AIED. This is exemplified by the themes 'Teacher knowledge and professional development' and 'Interaction and relationships'. Researchers/developers, on their side, seemed to be more focused on themes such as 'Individualization', 'Knowledge of technology' and 'Economic interests'. Below, we discuss the most common AIED themes.

Table 1 AIED: overview of themes and frequencies

\begin{tabular}{lccc}
\hline Themes & Teachers & Researchers/developers & Total \\
\hline Teacher knowledge and professional development & 36 & 20 & 56 \\
Individualization & 8 & 21 & 29 \\
The role of the teacher & 15 & 14 & 29 \\
Knowledge of technology & 0 & 15 & 15 \\
Ethical concerns & 5 & 9 & 14 \\
Economic interests & 2 & 10 & 12 \\
Interaction and relationships & 9 & 0 & 9 \\
Demand-driven design & 0 & 8 & 8 \\
Implementation, development and management & 8 & 0 & 8 \\
Other & 5 & 2 & 7 \\
Capacities & 5 & 0 & 5 \\
Equality & 2 & 3 & 5 \\
Meta-level & 0 & 5 & 5 \\
\hline
\end{tabular}




\section{Teacher Knowledge and Professional Development}

Overall, the commonest theme discussed in relation to AIED was teacher knowledge and professional development (56 comments). This theme gathered comments focussing on the need for knowledge about AIED but also comments regarding how to use AIED in the K-12 classroom. There are, however, few examples of more concrete ideas what kind of knowledge or development will be needed. The comments are suggesting the need for more knowledge without further specifications. One possible explanation is that the view of AIED can be vague. The following are examples of the need for professional development: 'Education in which type of AI that we should use and how we should use it', 'Knowledge about AI' and 'education, education, education'. There are some comments in this theme providing examples of possible drawbacks. For example, one teacher posed the following question: 'Is it possible to create AI that is complex enough (for the educational environment)?' Another example is: 'What is 'good' AI?'. We have to find AI that will fit education within K12 schools. One interesting difference between the researchers and the teachers is that the researchers to a greater extent describe the importance of collaboration between researchers, teachers and ed-tech companies.

\section{Individualization}

A major theme brought up in the discussions was individualization in classroom teaching, emphasized in curricula and challenging for teachers to achieve in practice. The teacher groups (8 comments) had expectations that AIED will 'make it easier to individualize teaching', but above all, it was the researcher/ developer groups $(21$ comments) that discussed ideas on AIED in relation to individualization. In one group it was suggested that AI technology will enable 'individualized teaching' and that 'some teaching elements can be individualized'. In other researcher/developer groups, there were questions about AIED in relation to individualization. Will it lead to 'more individualized teaching?' and 'individualized teaching - new dissemination within the group and how do we (teachers) handle it?'

It was also imagined, especially in the teacher groups, that AIED will function as a digital assistant in the teaching practice that helps students with, for example, 'language learning and quantity training'. In some of the teacher groups, the use of AIED in the K-12 classroom was associated with particular groups of students: 'It will be as a resource in the classroom (for the older students)', and it can give 'opportunities for students who do not receive sufficient information at school.' Moreover, AIED was also imagined as a digital colleague that could help teachers to 'map student's need for individualization', 'see the students' best way to learn', and to 'find out things that we have not seen before; automation, learning increases, "simplify" everyday life', and provide 'home education.' In the researcher/developer groups, it was suggested that AIED will assist the teacher with grading material in the assessment process: "the teacher can obtain more data to support the assessment since the AI has already done the job prior to grading'. 


\section{The Role of the Teacher}

The theme 'The role of the teacher' also collected 29 comments. One joint opinion in this theme was that teachers as well as researchers/developers seemed to agree about an uncertain future of the role of the teacher in the K-12 classroom: 'What is the (new) role of the teacher?' According to the groups consisting of researchers/developers, AIED might 'challenge the identity of the profession' and might lead to 'joy, productivity or less work'. In comments written by teachers, advantages of AIED such as supporting teaching generally could be noticed. Other advantages of AIED in teaching and learning discussed by teachers were related to assessment: 'Can we achieve automatized assessment?' Amongst developers, there/developers, there were various ethical concerns: 'Who is in charge of unsuccessful teaching? Teachers? AI? Developers?', 'What is true if the teacher and AI do not agree?' In contrast, teachers as codesigners were pointed out in one of the groups with researchers/developers: 'How can we help tutors act as (co)-designers of adaptive e-learning courses?' Moreover, some of the groups with teachers gave positive examples of AIED in the classroom such as 'language learning' and 'quantity training'. Other examples where teachers articulated the potential of AIED were the possibility for the technology to 'simplify the work [in the classroom]' and to be used in activities like 'home-based learning'. However, they experienced lack of control and knowledge of AIED: 'Can AI replace teachers?' and 'Are we teachers ready?'. With the future entry of AIED, teachers also raised concerns about how to prepare teacher trainees: 'How is the teacher training to be designed?' Researchers/developers problematized the concept of teaching and wonder whether, by means of AIED, 'you could diminish the importance of yourself in order to get more 'free' working time?'

\section{Comments on Educational Robots}

Discussions about ER rendered in total 182 comments (post-its) - 78 comments on 11 themes from the teachers and 104 comments on 14 themes from the researchers/developers (see Table 2). Some of the comments were coded in more than one theme. Comparing the frequencies indicated that the teachers to a greater extent focused on issues related to practical situations of teaching and learning, such as the themes 'Interaction and relationships', 'The students' and 'Teacher knowledge and professional development'. The researchers/developers more clearly emphasized theoretical issues on a meta-level, such as the themes 'Knowledge of technology', 'Teaching process', 'Capacities' and 'The role of the teacher'. In this context, the themes 'Teaching process' and 'The role of the teacher' may not be understood as primarily a very practical theme, but also a theme addressing comments of more overall focus. For instance, in the theme 'Teaching process', comments such as 'Discuss and reflect over purpose and goal with implementing robots in education' or 'What are challenges in designing activities with robots?' draw in this direction. Below, we discuss the commonest ER themes. 
Table 2 ER: overview of themes and frequencies

\begin{tabular}{llll}
\hline Themes & Teachers & Researchers/developers & Total \\
\hline Interaction and relationships & 16 & 11 & 27 \\
Knowledge of technology & 9 & 17 & 26 \\
Capacities & 9 & 13 & 22 \\
The students & 13 & 6 & 19 \\
Teacher knowledge and professional development & 9 & 8 & 17 \\
The role of the teacher & 6 & 11 & 16 \\
Teaching process & 0 & 15 & 15 \\
Practical examples & 8 & 5 & 13 \\
Technical challenges & 7 & 4 & 11 \\
Ethical concerns & 0 & 10 & 10 \\
Governance and implementation & 0 & 6 & 6 \\
Meta-level & 2 & 2 & 4 \\
Individualization & 3 & 1 & 4 \\
Economic interests & 0 & 3 & 2 \\
Equivalency & 0 & 2 & \\
\hline
\end{tabular}

\section{Interaction and Relationships}

The most prominent theme (27 comments) when taking the four groups with teachers and the five groups consisting of researchers/developers together is the theme 'Interaction and relationships'. This theme gathered comments focusing on the interaction and relationships between humans and ERs. The following are examples of issues that were highlighted on the post-it notes: 'Difficult to replace humanity and empathy' (teachers), 'How will students/children learn facial expressions if they interact with (faceless/expressionless) robots?' (researchers/developers) or 'Will the importance of relational competence disappear?' (researchers/developers). The theme included comments that pull in different directions, indicating that issues relating to the use of ERs in teaching and learning in the K-12 classroom are a complex, contextual and personal matter. For instance, the teachers highlighted that ER 'can stimulate children's empathic ability', but also expressed concerns that 'the communication becomes "scanty" and does not develop for the student'. While this theme is most prominent among the teachers - almost one-fifth of all comments - it is the fourth most prominent theme among the researchers/developers. This may strengthen the conclusion that the teachers are more focused on teaching practice.

\section{Knowledge of Technology}

'Knowledge of technology' is the most prominent theme among the researchers/ developers and the second most prominent theme if taking the teachers and the researchers/developers together (in total 26 comments). Comments by the groups consisting of researchers/developers in this theme addressed issues such as: 'What is 
the idea behind 'humanizing' software if the robot does not interact physically?', 'Why a human-like robot?' and 'What is the difference between a virtual robot and a physical robot?'. Teacher comments, for example, included the following: 'AI vs. robot, what is the difference?' and 'What do we know now? What should they be used for?' In the theme, comments draw on technical issues and the need to understand why and how ERs can be used, for instance, 'What are the challenges when designing activities with robots?' (researchers/developers) and 'What will they [ERs] be used for?' (teachers).

\section{Capacities}

The third most prominent theme is 'Capacities' (22 comments). This theme mainly focused on what added value ER bring to teaching and learning in the K-12 classroom. Comments such as 'never gets tired' (researchers/developers), 'will not be disappointed' (teachers) and 'do not lose patience' (teachers) were common among both the four groups of teachers and the five groups of researchers/developers. However, challenges were also addressed. Comments such as 'Frustration that the robot does not understand. How to handle 'breakdowns'?' (researchers/developers) and 'Limitation: Maybe they cannot vary the explanation model?' (teachers) relate to the fact that ER are automated and may have built-in shortcomings. developers, it was also noted that the/developers, it was also noted that the capacities of ER may be conceptualized differently mainly depending on the humans and 'age-related differences' and related to 'conceptions of the robot' or 'expectations on the robot'.

\section{Discussion}

This paper explores how teachers, researchers and pedagogical developers critically imagine and reflect upon the usage of AIED and ERs in education. The reason behind organizing the symposium and writing this paper is threefold-(1) the growing number of reports in the research literature on AIED and ER in the K-12 school; (2) the call in policy, theory and practice for teachers to develop enough digital competence and relate to such emergent technologies in an adequate way; and (3) the new role of the teacher that follows from these developments. In the literature, technologies such as AIED and ER have in various ways been described as having the potential to drive educational development (Alberola et al. 2016; Park and Han 2016) and to scaffold teaching practices (Edwards and Cheok 2018; Yun et al. 2013) and students' learning processes (Samani et al. 2017; Serholt 2017). Furthermore, there is a large body of parallel research targeting questions related to teachers' digital competences (for example Krumsvik 2008; Fransson et al. 2018; Lindberg and Olofsson 2018). In the light of the role of the teacher in K-12 postdigital education, digital competencies can provide practical and theoretical know-how for learning how to use digital technologies in a way where technology, pedagogy and content intertwine. This know-how can extend to identifying and acting upon ethical issues such as collection, storage and analyses of user information (e.g. the teacher and the student) by AIED and ER. In relation to this theoretical background, we briefly discuss the main findings related to the two research questions guiding the analysis. In this, the reflections individually written down and collaboratively discussed by the 65 participants in this study are understood as 
expressions of sociotechnical imaginaries (Williamson 2016) framed within postdigital K-12 education that avoid the distinction between digital and non-digital education (Fawns 2018).

\section{Artificial Intelligence in Education}

The analysis of the set of data related to the first research question identified a number of sociotechnical imaginaries that emerged when teachers and researchers/developers discussed AIED (see further Table 1). By far the most common theme was 'Teacher knowledge and professional development'. Especially teachers, but also researchers/ developers, argued that there is an extensive need for professional development if AIED is to be used in K-12 classrooms for teaching and learning activities. In fact, many teachers, and some researchers/developers, seemed to express a limited understanding of what AIED is, and in consequence it was difficult for them to imagine how to use AIED in the classroom. Drawing on this theme, future research could explore how to prepare teachers for using AIED in beneficial ways. In such efforts, and by drawing on the distinction between weak and strong AI (Lee and Shin 2017; Searle 1990), there seems to be a need to understand what is possible and realistic in the near future, and what is not.

Another common theme was 'individualization' where especially the researchers/ developers, but also some teachers, envisioned that AIED could be used in order to individualize education. The opportunity for individualization has also been suggested in previous research (Luckin et al. 2016). Notably, individualization was rarely mentioned when discussing ERs, indicating that the participants in our discussion groups mainly argued that AIED could be used to individualize teaching and learning in the classroom. Moreover, an equally common theme was 'The role of the teacher', in which both teachers and researchers/developers were actively engaged. They reflected on the role of the teacher in relation to both if, and when, AIED enters K-12 schools. Many comments on the post-it notes described how AIED could support and complement teachers, for example, in relation to the practice of assessment. However, there were also concerns with the potential conflictual roles between teachers and AIED. It was suggested by researchers/developers that it is essential that teachers become codesigners of AIED-supported activities in the classroom. This theme is also aligned with previous research. It has been suggested that teachers could shift to a 'guide on the side' (King 1993), to encourage collaboration (Luckin et al. 2016) and to support students in seeking, discussing and integrating information in a collaborative process (Roll and Wylie 2016). Future research is suggested in order to critically examine these potential opportunities.

As mentioned above, a key difference between AIED and ER was the potential for individualization, where especially the sociotechnical imaginaries of the researchers/ developers envisioned more opportunities with AIED in postdigital education. Other themes that seemed to have mainly been discussed regarding AIED, as compared with ER, were 'economic interests' and 'demand-driven design', which were both mainly brought up by the researchers/developers. Some worried that there are great economic interests at stake and consequently argued that AIED needs to be designed based on demands from teachers and students, which echoes previous concerns (Dreyfus and Dreyfus 1988; Player-Koro et al. 2018; Williamson 2016). 


\section{Educational Robots}

The analysis of the set of data related to the second research question identified sociotechnical imaginaries that emerged when teachers and researchers/ developers discussed ER. Previous research has reported that one of the key issues of ER is its social interactive capabilities (Serholt 2017). This was supported by our findings, where 'interaction and relationships' was the most prominent theme. Interestingly, this theme did not emerge from the AIED data. ER might be used to enable interaction and relationships, which in turn might affect human interaction and relationships in the classroom. 'Interaction and relationships' was of special interest to the teachers - almost a fifth of all teacher comments concerned this theme. Both teachers and researchers/ developers worried about the human and empathetic aspects of the relationship between ER and students. Thus, ER cannot be expected to address the increasing shortage of K-12 schoolteachers in the near future (Edwards and Cheok 2018; Morita et al. 2018) but are imagined as being used as yet-another digital technology in the classroom. In fact, it was argued that teachers would need to spend considerable time maintaining ER. Drawing from previous research and our findings, it is clear that one key focus of future research on ER should be on the interaction and relationships between ER, teachers and students. How sophisticated could the interactive social capabilities of ER be expected to be? What is the role of the teacher in complementing the limited social interactive capabilities of ER? How might the relationship between teachers and students be affected when introducing ER in the classroom?

'Knowledge of technology' was an almost equally frequent theme, in which many researchers/developers and teachers asked quite fundamental questions about ER, such as why and how we should use ER in the classroom. It seemed challenging to imagine how to use ER, when neither being quite sure what such a technology could be nor what type of teaching and learning activities it could facilitate. Also, it seemed not to be clear to the teachers and researchers/developers what the difference is between AIED and ER, and whether ER could be virtual, physical or both? Drawing on our findings, future research could explore challenges that occur when ER are implemented in the K-12 classroom. For example, Serholt (2017) found that teachers spend considerable time preparing and troubleshooting ER. From a teacher perspective, there seems to be a need to develop examples of what ER are or could be.

The third most common theme was 'Capacities'. There were positive examples, such as the idea that ER do not lose patience or will not be disappointed, but also challenges, such as the idea that there will be frustration when the ER do not understand or maybe might have difficulties explaining in different ways to each student, were adduced. Drawing on this theme, there seems to be a need for critical research that explores the benefits and limitations of using ER in classrooms.

Other themes that seemed mainly to have been discussed regarding ER, as compared with AIED, were 'The students', 'Practical examples' and 'Technical challenges'. In these sociotechnical imaginaries, especially teachers, but also researchers/developers, reflected on how students would be affected if there were ER in the classroom. Moreover, there seemed to be a need to provide practical examples in order to understand how ER could actually be used in teaching and learning in the postdigital 
K-12 classroom. Finally, there were reflections on the future challenge of how to address technical challenges with ER.

We believe a similar distinction can also be used when discussing sociotechnical imaginaries. Do our imaginaries stem from researchers/developers who are imagining ideal future technology-rich educational practices or from practitioners grounded in current practice? In this paper, we are combining and contrasting both perspectives.

\section{Conclusion}

This paper explores how teachers and researchers/developers critically imagine and reflect upon ways in which AI and robots could be used in education. There are some similarities, but also differences, between how AIED and ERs are reflected upon and discussed. In both cases, the need for more knowledge about these digital technologies, how they might preferably be used, and also how the emergence of these technologies might affect the role of the teacher, and the relationship between teachers and students, were adduced. Many participants saw more potential in using AIED for individualization, as compared with ERs. However, there were also more concerns, such as ethical issues and economic interests, when discussing AIED.

An overarching finding was that the teachers and researchers/developers have quite a limited understanding of what AIED and ERs actually are, and consequently how such advanced technologies could be used. It might be more challenging to critically examine something that you do not yet fully understand. It has been suggested that the complexity of problems associated with AI risks being overly simplified by optimism derived from economic interests in making AI a reality (Dreyfus and Dreyfus 1988). This could be compared with recent debates on more contemporary technologies, such as learning management systems and mobile phones, where many teachers and researchers/developers seem to have a clearer view. In line with previous research, teachers primarily discussed the state-of-the-actual, while researchers/developers discussed the state-of-the-art (Henderson et al. 2015) of ER. Teachers focused more on concrete teaching and learning practices as compared to the researchers/developers who focused on foundational educational issues and future visions. Future research is suggested in order to critically analyse the role of AIED and ERs in postdigital K-12 education. How will the emergence of these technologies affect the role of the teacher? How will the relationship between teachers and students be affected?

\section{Compliance with Ethical Standards}

Conflict of Interest The authors declare that they have no conflict of interest.

Open Access This article is distributed under the terms of the Creative Commons Attribution 4.0 International License (http://creativecommons.org/licenses/by/4.0/), which permits unrestricted use, distribution, and reproduction in any medium, provided you give appropriate credit to the original author(s) and the source, provide a link to the Creative Commons license, and indicate if changes were made. 


\section{References}

Alberola, J. M., del Val, E., Sanchez-Angui, V., Palomares, A., \& Dolores Teruel, M. (2016). An artificial intelligence tool for heterogeneous team formation in the classroom. Knowledge-Based Systems, 101, 114. https://doi.org/10.1016/j.knosys.2016.02.010.

Albion P.R., \& Tondeur J. (2018) Information and communication technology and education: meaningful change through teacher agency. In J. Voogt, G. Knezek, R. Christensen, \& K.W. Lai KW. (Eds.), Handbook of information technology in primary and secondary education (pp. 1-15). Cham: Springer. https://doi.org/10.1007/978-3-319-71054-9 25.

Alsoliman, B. S. H. (2018). The utilization of educational robotics in Saudi schools: potentials and barriers from the perspective of Saudi teachers. International Education Studies, 11(10), 105-111. https://doi. org/10.5539/ies.v11n10p105.

Asimov, I. (1941). Run around. Astounding Science Fiction, 29(1), 94-103.

Belpaeme, T., Kennedy, J., Ramachandran, A., Scassellati, B., \& Tanaka, F. (2018). Social robots for education: A review. Science Robotics, 3(21), eaat5954. https://doi.org/10.1126/scirobotics.aat5954.

Castelfranchi, C. (2013). Alan Turing's “computing machinery and intelligence". Topoi, 32(2), 293-299. https://doi.org/10.1007/s11245-013-9182-y.

Cheng, Y.-W., Sun, P.-C., \& Chen, N.-S. (2017). An investigation of the needs on educational robots. In 2017 IEEE 17th International Conference on Advanced Learning Technologies (ICALT) (pp. 536-538). Timisoara, Romania: IEEE. https://doi.org/10.1109/ICALT.2017.115.

Chevalier, M., Riedo, F., \& Mondada, F. (2016). How do teachers perceive educational robots in formal education? A study based on the Thymio robot. IEEE Robotics and Automation Magazine, 1070(9932/16), 1-8.

Dreyfus, H. L., \& Dreyfus, S. E. (1988). Mind over machine: the power of human intuition and expertise in the era of the computer. New York: The Free Press.

Edwards, B. I., \& Cheok, A. D. (2018). Why not robot teachers: artificial intelligence for addressing teacher shortage. Applied Artificial Intelligence, 32(4), 345-360. https://doi.org/10.1080/08839514.2018. 1464286.

Edwards, C., Edwards, A., Spence, P. R., \& Lin, X. (2018). I, teacher: using artificial intelligence (AI) and social robots in communication and instruction. Communication Education, 67(4), 473-480. https://doi. org/10.1080/03634523.2018.1502459.

Fawns, T. (2018). Postdigital education in design and practice. Postdigital Science and Education, 1(1), 132145. https://doi.org/10.1007/s42438-018-0021-8.

Fransson, G., Lindberg, J. O., \& Olofsson, A. D. (2018). Adequate digital competence - a close reading of the new national strategy for digitalization of the schools in Sweden. Seminar.net: Media, Technology \& Lifelong Learning, 14(2), 217-228.

Heffernan, N. T., \& Heffernan, C. L. (2014). The ASSISTments ecosystem: building a platform that brings scientists and teachers together for minimally invasive research on human learning and teaching. International Journal of Artificial Intelligence in Education, 24(4), 470-497. https://doi.org/10.1007 /s40593-014-0024-x.

Henderson, M., Selwyn, N., Finger, G., \& Aston, R. (2015). Students' everyday engagement with digital technology in university: exploring patterns of use and 'usefulness'. Journal of Higher Education Policy and Management, 37(3), 308-319. https://doi.org/10.1080/1360080X.2015.1034424.

Hill, C., Creswell, C., Vigerland, S., Nauta, M. H., March, S., Donovan, C., Wolters, L., Spence, S. H., Martin, J. L., Wozney, L., McLellan, L., Kreuze, L., Gould, K., Jolstedt, M., Nord, M., Hudson, J. L., Utens, E., Ruwaard, J., Albers, C., Khanna, M., Albano, A. M., Serlachius, E., Hrastinski, S., \& Kendall, P. C. (2018). Navigating the development and dissemination of internet cognitive behavioral therapy (iCBT) for anxiety disorders in children and young people: a consensus statement with recommendations from the \# iCBTLorentz Workshop Group. Internet Interventions, 12, 1-10. https://doi.org/10.1016/j. invent.2018.02.002.

Jahnke, I., Bergström, P., Mårell-Olsson, E., \& Häll, L. (2017). Digital didactical designs as research framework: iPad integration in Nordic schools. Computers \& Education, 113, 1-15. https://doi. org/10.1016/j.compedu.2017.05.006.

Jandrić, P. (2019a). Welcome to postdigital science and education! Postdigital Science and Education, 1(1), 13. https://doi.org/10.1007/s42438-018-0013-8.

Jandrić, P., Ryberg, T., Knox, J., Lacković, N., Hayes, S., Suoranta, J., Smith, M., Steketee, A., Peters, M., McLaren, P., Ford, D. R., Asher, G., McGregor, C., Stewart, G., Williamson, B., \& Gibbons, A. (2019b). 
Postdigital dialogue. Postdigital Science and Education, 1(1), 163-189. https://doi.org/10.1007/s42438018-0011-x.

Jensen, T. (2017). Ramon Llull's Ars magna. In R. Moreno-Diaz, A. Quesada-Arencibia, \& F. Pichler (Eds.), EUROCAST: international conference on computer aided systems theory (pp. 19-24). Cham: Springer. https://doi.org/10.1007/978-3-319-74718-7 3.

King, A. (1993). From sage on the stage to guide on the side. College Teaching, 41(1), 30-35.

Koedinger, K. R., \& Corbett, A. T. (2006). Cognitive tutors: technology bringing learning science to the classroom. In K. Sawyer (Ed.), The Cambridge handbook of the learning sciences (pp. 61-78). New York: Cambridge University Press.

Krumsvik, R. J. (2008). Situated learning and teachers' digital competence. Education and Information Technologies, 13(13), 279-290. https://doi.org/10.1007/s10639-008-9069-5.

Krumsvik, R. J., Jones, L. Ø., Øfstegaard, M., \& Eikeland, O. J. (2016). Upper secondary school teachers' digital competence: analysed by demographic, personal and professional characteristics. Nordic Journal of Digital Literacy, 11(3), 143-164. https://doi.org/10.18261/issn.1891-943x-2016-03-02.

Lantz-Andersson, A., Peterson, L., Hillman, T., Lundin, M., \& Rensfeldt, A. B. (2017). Sharing repertoires in a teacher professional Facebook group. Learning, Culture and Social Interaction, 15, 44-55. https://doi. org/10.1016/j.lcsi.2017.07.001.

Lee, S., \& Shin, Y. (2017). The direction of information security control analysis using artificial intelligence. In J. J. Park, V. Loia, G. Yi, \& Y. Sung (Eds.), Advances in computer science and ubiquitous computing (pp. 872-877). Singapore: Springer. https://doi.org/10.1007/978-981-10-7605-3 138.

Lindberg, O. J., \& Olofsson, A. D. (2018). Editorial - recent trends in the digitalization of the Nordic K-12 schools. Seminar.net. Media, Technology \& Lifelong Learning, 14(2), 103-108.

Luckin, R., Holmes, W., Griffiths, M., \& Forcier, L. B. (2016). Intelligence unleashed: an argument for AI in education. Resource document. https://static.googleusercontent.com/media/edu.google. com/sv//pdfs/Intelligence-Unleashed-Publication.pdf Accessed January 2019.

McCarthy, J., Minsky, M. L., Rochester, N., \& Shannon, C. E. (2006). A proposal for the Dartmouth summer research project on artificial intelligence, august 31, 1955. AI Magazine, 27(4), 12-14.

Morita, T., Akashiba, S., Nishimoto, C., Takahashi, N., Kukihara, R., Kuwayama, M., \& Yamaguchi, T. (2018). A practical teacher-robot collaboration lesson application based on PRINTEPS. The Review of Socionetwork Strategies, 12(1), 97-126. https://doi.org/10.1007/s12626-018-0021-x.

Mubin, O., Stevens, C. J., Shahid, S., Mahmud, A. A., \& Dong, J.J. (2013). A review of the applicability of robots in education. Technology for Education and Learning, 1(1). Resource document. https://pdfs. semanticscholar.org/b2bf/e4c19bc4873f469297847d80dbc684d0807a.pdf Accessed 21 Dec 2018.

Pandey, A. K., \& Gelin, R. (2017). Humanoid robots in education: a short review. In A. Goswami \& P. Vadakkepat (Eds.), Humanoid robotics: a reference (pp. 1-16). Dordrecht: Springer. https://doi. org/10.1007/978-94-007-7194-9_113-1.

Park, I.-W., \& Han, J. (2016). Teachers' views on the use of robots and cloud services in education for sustainable development. Cluster Computing, 19(2), 987-999. https://doi.org/10.1007/s10586-016-0558-9.

Player-Koro, C., Bergviken Rensfeldt, A., \& Selwyn, N. (2018). Selling tech to teachers: education trade shows as policy events. Journal of Education Policy, 33(5), 682-703. https://doi.org/10.1080 /02680939.2017.1380232.

Prestridge, S. (2012). The beliefs behind the teacher that influences their ICT-practices. Computers \& Education, 58(1), 449-458. https://doi.org/10.1016/j.compedu.2011.08.028.

Roll, I., \& Wylie, R. (2016). Evolution and revolution in artificial intelligence in education. International Journal of Artificial Intelligence in Education, 26(2), 582-599. https://doi.org/10.1007/s40593-016-0110-3.

Samani T., Porayska-Pomsta K., \& Luckin R. (2017). Bridging the gap between high and low performing students through performance learning online analysis and curricula. In E. André, R. Baker, X. Hu, M. Rodrigo, and B. du Boulay (Eds.), Artificial intelligence in education (pp. 650-655). AIED 2017. Lecture Notes in Computer Science, vol. 10331. Cham: Springer. https://doi.org/10.1007/978-3-319-61425-0_82.

Sayous, P. (2009). Trailer of the DVD “the Jaquet-Droz androids" [Video file]. https://youtu.be/vr0e_WsjkvY. Accessed 29 April 2019.

Searle, J. R. (1990). Is the brain's mind a computer program. Scientific American, 262(1), 25-31.

Serholt, S. (2017). Child-robot interaction in education. PhD thesis. Gothenburg: University of Gothenburg.

Serholt, S., Barendregt, W., Vasalou, A., Alves-Oliveira, P., Jones, A., Petisca, S., \& Paiva, A. (2017). The case of classroom robots: teachers' deliberations on the ethical tensions. AI \& Society, 32(4), 613-631. https://doi.org/10.1007/s00146-016-0667-2.

Sharkey, A. J. C. (2016). Should we welcome robot teachers? Ethics and Information Technology, 18(4), 283297. https://doi.org/10.1007/s10676-016-9387-z. 
Siciliano, B., \& Khatib, O. (2018). Humanoid robots: historical perspective, overview and scope. In A. Goswami \& P. Vadakkepat (Eds.), Humanoid robotics: a reference (pp. 1-6). Dordrecht: Springer. https://doi.org/10.1007/978-94-007-6046-2_64.https://doi.org/10.1007/978-94-007-6046-2_64.

Tegmark, M. (2017). Life 3.0: being human in the age of artificial intelligence. New York: Knopf.

Turing, A. M. (1937). On computable numbers, with an application to the Entscheidungs problem. Proceedings of the London Mathematical Society, 2(1), 230-265.

Turing, A. M. (1950). Computing machinery and intelligence. Mind, 54(236), 433-460.

VanLehn, K. (2011). The relative effectiveness of human tutoring, intelligent tutoring systems, and other tutoring systems. Educational Psychologist, 46(4), 197-221. https://doi.org/10.1080 /00461520.2011.611369.

Williamson, B. (2016). Boundary brokers: mobile policy networks, database pedagogies, and algorithmic governance in education. In T. Ryberg, C. Sinclair, S. Bayne, \& M. de Laat (Eds.), Research, boundaries, and policy in networked learning (pp. 41-57). Cham: Springer. https://doi.org/10.1007/978-3-319-3113023 .

Yun, S.-S., Kim, M., \& Choi, M.-T. (2013). Easy interface and control of tele-education robots. International Journal of Social Robotics, 5(3), 335-343. https://doi.org/10.1007/s12369-013-0192-0.

\title{
Affiliations
}

Stefan Hrastinski ${ }^{1}$ - Anders D. Olofsson ${ }^{2}$ • Charlotte Arkenback ${ }^{3}$ - Sara Ekström ${ }^{4}$. Elin Ericsson ${ }^{3} \cdot$ Göran Fransson $^{5}$ - Jimmy Jaldemark ${ }^{6} \cdot$ Thomas Ryberg $^{7}$. Lena-Maria Öberg ${ }^{8}$ - Ana Fuentes ${ }^{4}$ - Ulrika Gustafsson ${ }^{2} \cdot$ Niklas Humble $^{8} \cdot$ Peter $^{-}$ Mozelius $^{8} \cdot$ Marcus Sundgren $^{6} \cdot$ Marie Utterberg $^{3}$

\author{
Anders D. Olofsson \\ anders.d.olofsson@umu.se \\ Charlotte Arkenback \\ charlotte.arkenback-sundstrom@ait.gu.se \\ Sara Ekström \\ sara.ekstrom@hv.se \\ Elin Ericsson \\ elin.ericsson@ait.gu.se \\ Göran Fransson \\ goran.fransson@hig.se \\ Jimmy Jaldemark \\ jimmy.jaldemark@miun.se \\ Thomas Ryberg \\ ryberg@hum.aau.dk \\ Lena-Maria Öberg \\ lena-maria.oberg@miun.se \\ Ana Fuentes \\ ana.fuentes-martinez@hv.se \\ Ulrika Gustafsson \\ ulrika.gustafsson@umu.se \\ Niklas Humble \\ niklas.humble@miun.se
}


Peter Mozelius

Peter.Mozelius@miun.se

Marcus Sundgren

marcus.sundgren@miun.se

Marie Utterberg

marie.utterberg@ait.gu.se

1 Division of Digital Learning, KTH Royal Institute of Technology, Stockholm, Sweden

2 Department of Applied Educational Science, Umeå University, Umeå, Sweden

3 Department of Applied IT, University of Gothenburg, Gothenburg, Sweden

4 Department of Economics and IT, University West, Trollhättan, Sweden

5 Faculty of Education and Business Studies, University of Gävle, Gävle, Sweden

6 Department of Education, Mid Sweden University, Sundsvall, Sweden

7 Department of Communication and Psychology, Aalborg University, Aalborg, Denmark

8 Department of Computer and System Science, Mid Sweden University, Östersund, Sweden 